\title{
Nitro-substituted tetrahydroindolizines and homologs: Design, kinetics, and mechanism of $\alpha$-glucosidase inhibition
}

\author{
Cinzia Tavani ${ }^{\mathrm{a}, *}$, Lara Bianchi ${ }^{\mathrm{a}}$, Annalisa De Palma ${ }^{\mathrm{b}}$, Giovanna Ilaria Passeri ${ }^{\mathrm{c}}$, Giuseppe Punzi ${ }^{\mathrm{b}}$, \\ Ciro Leonardo Pierri ${ }^{\mathrm{b}}$, Angelo Lovece ${ }^{\mathrm{c}}$, Maria Maddalena Cavalluzzi ${ }^{\mathrm{c}}$, Carlo Franchini ${ }^{\mathrm{c}}$, Giovanni Lentini ${ }^{\mathrm{c}, *}$, \\ Giovanni Petrillo ${ }^{a}$
}

${ }^{a}$ Department of Chemistry and Industrial Chemistry, University of Genoa, Via Dodecaneso 31, I-16146 Genoa, Italy

${ }^{\mathrm{b}}$ Department of Biosciences, Biotechnologies, and Biopharmaceutics, University of Bari Aldo Moro, via E. Orabona 4, 70126 Bari, Italy

${ }^{\mathrm{c}}$ Department of Pharmacy - Drug Sciences, University of Bari Aldo Moro, via E. Orabona 4, 70126 Bari, Italy

\section{A R T I C L E I N F O}

\section{Article history}

Received 20 May 2017

Revised 18 July 2017

Accepted 26 July 2017

Available online 27 July 2017

\section{Keywords:}

Tetrahydroindolizines

$\alpha$-Glucosidase inhibitors

Molecular docking

Circular dichroism

Ligand efficiency metrics

\begin{abstract}
A B S T R A C T
A series of 1-[(methylsulfonyl)methyl]-2-nitro-5,6,7,8-tetrahydroindolizines and homologs were designed, prepared, and evaluated as non-sugar-type $\alpha$-glucosidase inhibitors. The inhibitory activity appeared to be related to cyclo homologation with the best congeners being tetrahydroindolizines. The introduction of a methoxycarbonyl group as an additional hydrogen bond acceptor into the exocyclic methylene group was beneficial affording the most potent congener $\mathbf{3 e}$ (half maximal inhibitory concentration, $\mathrm{IC}_{50}=8.0 \pm 0.1 \mu \mathrm{M}$ ) which displayed 25 -fold higher inhibitory activity than 1-deoxynojirimycin $\left(\mathbf{2}, \mathrm{IC}_{50}=203 \pm 9 \mu \mathrm{M}\right)$-the reference compound. Kinetic analysis indicated that compound $\mathbf{3 e}$ is a mixed inhibitor with preference for the free enzyme over the $\alpha$-glucosidase-substrate complex $\left(K_{\mathrm{i}, \text { free }}=3.6 \mu \mathrm{M}\right.$; $K_{\mathrm{i}, \text { bound }}=7.6 \mu \mathrm{M}$ ). Molecular docking experiments were in agreement with kinetic results indicating reliable interactions with both the catalytic cleft and other sites. Circular dichroism spectroscopy studies suggested that the inhibition exerted by $3 \mathbf{e}$ may involve changes in the secondary structure of the enzyme. Considering the relatively low molecular weight of $\mathbf{3 e}$ together with its high fraction of $\mathrm{sp}^{3}$ hybridized carbon atoms, this nitro-substituted tetrahydroindolizine may be considered as a good starting point towards new leads in the area of $\alpha$-glucosidase inhibitors.
\end{abstract}

(c) 2017 Elsevier Ltd. All rights reserved.
$\alpha$-Glucosidases (EC 3.2.1, $\alpha$-D-glucoside glucohydrolases) are enzymes that catalyze the hydrolysis of $\alpha$-glycosidic linkages at the non-reducing ends of glucose multimers. ${ }^{1}$ These glucoside hydrolases are ubiquitary in living beings and are involved in several basic biochemical pathways, including carbohydrate digestion, glycogen degradation, and both glycoprotein and glycoconjugates maturation. The first group of reactions constitutes a fundamental step for glucose absorption: intestinal $\alpha$-glucosidases break down diet polysaccharides and oligosaccharides to glucose, while $\alpha$-glucosidase inhibition delays glucose absorption, reducing post-prandial plasma glucose levels. ${ }^{2}$ Through the second type of reactions, endocellular $\alpha$-glucosidases promote the liberation of D-glucose units from glycogen stores. Indeed, inborn deficiency of endocellular $\alpha$-glucosidase activity causes glycogenosis. ${ }^{3}$ Finally,

\footnotetext{
* Corresponding authors.

E-mail addresses: cinzia.tavani@chimica.unige.it (C. Tavani), giovanni.lentini@ uniba.it (G. Lentini).
}

the action of $\alpha$-glucosidases in the endoplasmic reticulum has synthetic fall-out because these enzymes are involved in the synthesis of glycoconjugates that are necessary for mammalian cell growth and proliferation. ${ }^{4}$ The same enzymatic activity is involved in the morphogenesis of many enveloped viruses where host functions are essential for viral replication. In fact, suppression of $\alpha$-glucosidase activity at the endoplasmic reticulum level through expression inhibition with interfering RNA reduces the formation of enveloped RNA viruses. ${ }^{5}$

$\alpha$-Glucosidases inhibitors have been proposed for the treatment of several pathological states such as hyperglycemia in type 2 diabetes mellitus, ${ }^{6}$ body mass increase $^{7}$ and post-prandial hyperglycemia ${ }^{8}$ in type 1 diabetes mellitus, gestational diabetes, ${ }^{9}$ prediabetes, ${ }^{10}$ weight gain ${ }^{11}$ and cardiovascular events ${ }^{12}$ in type 2 diabetic patients, cancer, ${ }^{13}$ cystic fibrosis, ${ }^{14}$ overproduction of melanin,${ }^{15}$ ulcerative colitis, ${ }^{16}$ glycosphingolipid lysosomal storage diseases, ${ }^{17}$ Tangier disease, ${ }^{18}$ and viral infections. ${ }^{19}$ 
<smiles>[R]C(C)C(O)C(C([R])C([R])O)N(C)C</smiles>

$1 a, b$

a: $n=0$, pyrrolizidines

b: $n=1$, indolizidines<smiles>OCC1NC[C@@H](O)[C@H](O)[C@H]1O</smiles>

2

1-deoxynojirimicin (DNJ)<smiles>[R]CS(=O)(=O)C([R])c1c([N+](=O)[O-])cn2c1CCCC2</smiles>

\section{$3 a-\mathbf{i}$}

Fig. 1. Structures of alkaloids (1a,b), 1-deoxynojirimicin (DNJ, 2), and title compounds (3a-i) acting as $\boldsymbol{\alpha}$-glucosidase inhibitors.
Numerous $\alpha$-glucosidase inhibitors have been reported but few of them have clinical relevance. ${ }^{20}$ Looking for $\alpha$-glucosidase inhibitors possibly endowed with high ligand efficiency metrics, ${ }^{21}$ we focused on a relatively prodigal class of naturally occurring perhydro bicyclic ring systems (Fig. 1) that consist of two fused pyrrolidine rings sharing their nitrogen atoms (pyrrolizidines, 1a, $\mathrm{n}=0$ ) and the nitrogen-bridgehead nucleus homologs resulting from the fusion between a pyrrolidine and a piperidine rings (indolizidines, $\mathbf{1 b}, \mathrm{n}=1$ ).

These alkaloids display from moderate to high inhibiting potency (half maximal inhibitory concentration, $\mathrm{IC}_{50}=70-$ $0.1 \mu \mathrm{M})^{22}$ but deep investigation of their pharmacological profiles is hampered by several shortcomings. Since they present a relatively high number of configurationally stable chirality centers, biological activity exploration for all possible theoretical isomers would represent a formidable task. Preparation of suitable quantities should go through either tedious, time-consuming multi-step extraction processes from natural sources or sophisticated synthetic procedures. ${ }^{23}$ Their relatively high cost impairs wide exploration of their in vitro and in vivo pharmacological profiles. Alkaloids 1a,b may be considered as annulated analogs of 1deoxynojirimycin (DNJ, 2), a well-known $\alpha$-glucosidase inhibitor $\left(\mathrm{IC}_{50}=52 \pm 2 \mu \mathrm{M}\right)^{24}$ that has not entered clinical use. Iminosugars such as $\mathbf{2}$ are water soluble and display pH dependent inhibitory activity. ${ }^{25,26}$ As a consequence, both pharmacodynamics and pharmacokinetics are erratic. ${ }^{27}$ Finally, protonatable rings generally cause promiscuity ${ }^{28}$ and human ether-à-go-go-related gene (hERG) channel inhibition. ${ }^{29}$

We have recently developed a synthetic procedure to obtain fused $[1,2-a]$ pyrroles of general formula 3 (Fig. 1$)^{30}$ that may be considered as unsaturated analogs of $\mathbf{1 a}, \mathbf{b}$. We hypothesized that these annulated nitropyrroles might amend some of the structural drawbacks of the bicyclic reference compounds. The pyrrole

Table 1

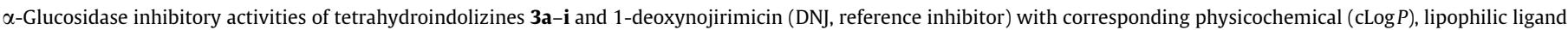
efficiency (LLE), and structural $\left(\mathrm{Fsp}^{3}\right)$ metrics.<smiles>[R]CS(=O)(=O)C([R])c1c([N+](=O)[O-])cn2c1CCCC2</smiles>

$3 \mathbf{a}-\mathbf{i}$

\begin{tabular}{|c|c|c|c|c|c|c|c|}
\hline Compd & $\mathrm{n}$ & $\mathrm{R}^{1}$ & $\mathrm{R}^{2}$ & $\mathrm{IC}_{50} \pm \mathrm{SEM}^{\mathrm{a}}$ & $\mathrm{c} \log P^{\mathrm{b}}$ & $\mathrm{LLE}^{\mathrm{C}}$ & $\mathrm{Fsp}^{3}$ \\
\hline $3 a$ & 0 & $\mathrm{H}$ & $\mathrm{H}$ & $>150^{d}$ & 0.99 & 2.8 & 0.56 \\
\hline 3b & 1 & $\mathrm{H}$ & $\mathrm{H}$ & $72 \pm 6$ & 1.6 & 2.5 & 0.60 \\
\hline $3 c$ & 2 & $\mathrm{H}$ & $\mathrm{H}$ & $>300^{\mathrm{e}}$ & 2.1 & 1.4 & 0.64 \\
\hline 3d & 0 & $\mathrm{CO}_{2} \mathrm{Me}$ & $\mathrm{H}$ & $48 \pm 1$ & 1.6 & 2.7 & 0.54 \\
\hline $3 e$ & 1 & $\mathrm{CO}_{2} \mathrm{Me}$ & $\mathrm{H}$ & $8.0 \pm 0.10$ & 2.2 & 2.9 & 0.58 \\
\hline $3 f$ & 2 & $\mathrm{CO}_{2} \mathrm{Me}$ & $\mathrm{H}$ & $124 \pm 8$ & 2.8 & 1.1 & 0.62 \\
\hline $3 g$ & 1 & $\mathrm{H}$ & $\mathrm{Ph}$ & $29.0 \pm 0.2$ & 3.4 & 1.1 & 0.38 \\
\hline $3 h$ & 1 & $\mathrm{CO}_{2} \mathrm{Me}$ & $\mathrm{Ph}$ & $19.8 \pm 1.5$ & 4.2 & 0.5 & 0.39 \\
\hline $3 \mathbf{i}$ & 1 & $\mathrm{CO}_{2} \mathrm{Me}$ & p-MePh & $65 \pm 4$ & 4.6 & -0.4 & 0.42 \\
\hline DNJ (2) & & & & $203 \pm 9^{f}$ & -2.1 & 5.8 & 1.0 \\
\hline
\end{tabular}

a Compound concentration ( $\mu \mathrm{M}$, means \pm SEM of three determinations) responsible for $50 \%$ inhibition of $\alpha$-glucosidase activity.

b Generated using the ACD/Labs Percepta Platform-PhysChem Module (ACD/Labs, Toronto, ON, Canada).

${ }^{c}$ Lipophilic ligand efficiency $\left(\operatorname{LLE}=\operatorname{pIC}_{50}-\operatorname{cLog} P\right) .{ }^{37}$

d $46 \%$ inhibition at $150 \mu \mathrm{M}$.

e no inhibition at $300 \mu \mathrm{M}$.

${ }^{f}$ Lit: $52 \pm 2 \mu \mathrm{M}^{24}$ 


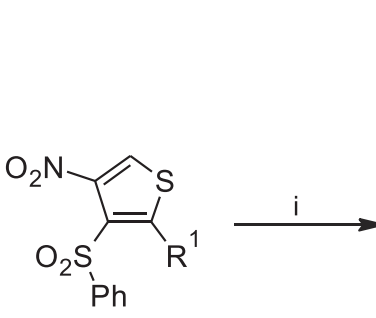

4a: $\mathrm{R}^{1}=\mathrm{H}$

4b: $\mathrm{R}^{1}=\mathrm{CO}_{2} \mathrm{Me}$

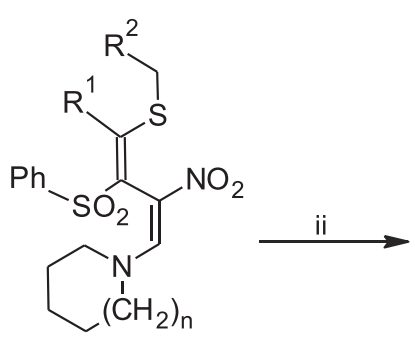

$5 a-i$

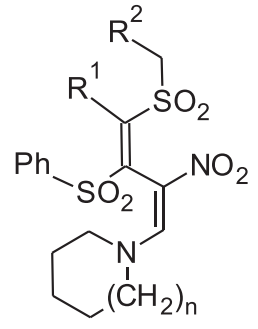

$6 a-i$

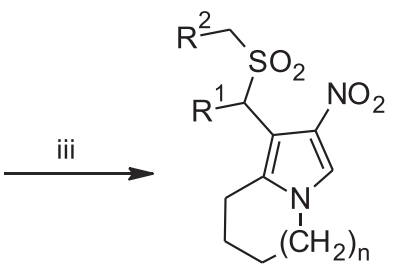

$3 a-i$

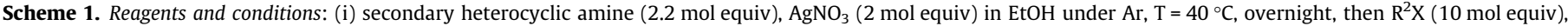
$4 \mathrm{~h}$; (ii) m-CPBA (1.1 mol equiv) in DCM, rt; (iii) reflux in EtOH for 3-7 h.

nitrogen atom in $\mathbf{3 a - i}$ is not protonatable at physiological $\mathrm{pH}$ and the only chirality center, where present (3d-f,h,i, Table 1 ), is configurationally unstable (no need/possibility to obtain and study separated enantiomers). As peculiarly found in several naturally occurring compounds, ${ }^{31}$ both homolog series 1a,b present high fraction of $\mathrm{sp}^{3}$ hybridized carbon atoms $\left(\mathrm{Fsp}^{3}=1\right)$, a property generally granting clinical developability (suggested $\mathrm{Fsp}^{3} \geq 0.36$ ). ${ }^{32}$ The introduction of a few $\mathrm{sp}^{2}$ hybridized carbon atoms should be well tolerated. Furhermore, $\mathbf{1} \mathbf{a}, \mathbf{b}$ and $\mathbf{3 a} \mathbf{a}-\mathbf{i}$ share the same number of 'lean' rings (i. e., heterocycles), ${ }^{33}$ another beneficial structural feature. ${ }^{29}$ While further reducing basicity, the nitro group would improve inhibiting potency. ${ }^{24}$ The sulfonyl and methoxycarbonyl groups would offer additional hydrogen bond accepting opportunities while tuning the lipophilic/hydrophilic balance. Finally, the benzylsulfonyl analogs would confer advantages from van der Waals/stacking interactions possibly involved in the binding process.

The target compounds were obtained through the route depicted in Scheme 1. ${ }^{30}$

Nitrothiophenes $\mathbf{4} \mathbf{a}^{34}$ or $\mathbf{4} b^{34,35}$ were treated with an excess of the suitable secondary amine (pyrrolidine, piperidine or azepane) and $\mathrm{AgNO}_{3}$ in EtOH under $\mathrm{Ar}$, at $40^{\circ} \mathrm{C}$. The silver enethiolate so generated was then added with the alkylating agent [MeI, benzylbromide, or 1-(bromomethyl)-4-methylbenzene] to obtain the nitroenamines $\mathbf{5 a} \mathbf{a}-\mathbf{i}$. The mercapto group was then oxidized at sulfur with $m$-CPBA to obtain the corresponding sulfones $\mathbf{6 a - i}$. Finally, the title compounds $\mathbf{3 a}-\mathbf{i}$ were easily obtained in generally high yields by refluxing the relevant $\mathbf{6 a}-\mathbf{i}$ in ethanol and rapidly isolat- ing the precipitate by filtration. After recrystallization, the structures of the target compounds $\mathbf{3 a} \mathbf{a}-\mathbf{i}$ were elucidated using spectroscopic and spectrometric analyses.

As anticipated, compounds $\mathbf{3 a - i}$ have $\mathrm{Fsp}^{3}$ signatures higher than optimal suggested values (Table 1$)^{32}$ and were evaluated for their in vitro $\alpha$-glucosidase inhibitory activity using $\mathbf{2}$ (DNJ) as a reference compound (Table 1 ). Seven out of nine compounds were significantly more potent than DNJ (comparisons between potency values were supported by the two tails Student's t-test; $p<0.01$ ) in a concentration-dependent manner. Potency depended on homologation with the best $\mathrm{n}$ value being 1 (tetrahydroindolizines, $\mathrm{cf}$. 3ac; 3d-f). These results are in agreement with what previously reported for iminoalditols and thioisosteres where homologation strongly regulated activity probably as a consequence of ring flexibility. ${ }^{36}$ The most potent congener 3e displayed 25-fold higher inhibitory activity than DNJ. The general improvement in potency was obviously related to increasing lipophilicity (see $\operatorname{cLog} P$ values in Table 1). However, lipophilic ligand efficiency $\left(\mathrm{LLE}=\mathrm{pIC}_{50}-\right.$ $\operatorname{cLog} P)^{37}$ values, while being lower than LLE of DNJ, were maintained in the most active analogs (Table 1). Thus the observed gain in potency should not correspond to loss of binding specificity. ${ }^{37}$

The ligand efficiency $\left(\mathrm{LE}=1.37 \mathrm{pIC}_{50} / \mathrm{HA}\right.$ where $\mathrm{HA}$ is the number of non-hydrogen atoms $)^{38}$ score was maintained throughout the study (Fig. 2). However, the introduction of a phenyl group to obtain the benzylsulfonyl analog $\mathbf{3 g}$ was not as beneficial as homologation (3b) or insertion of the methoxycarbonyl group (3e), as attested by group efficiency $\left(\mathrm{GE}=\Delta \Delta \mathrm{G} / \Delta \mathrm{HA}=\Delta 1.37 \mathrm{pIC}_{50} /\right.$ $\Delta H A)^{39}$ scores (Fig. 2). Furthermore, the effects of methoxycarbonyl

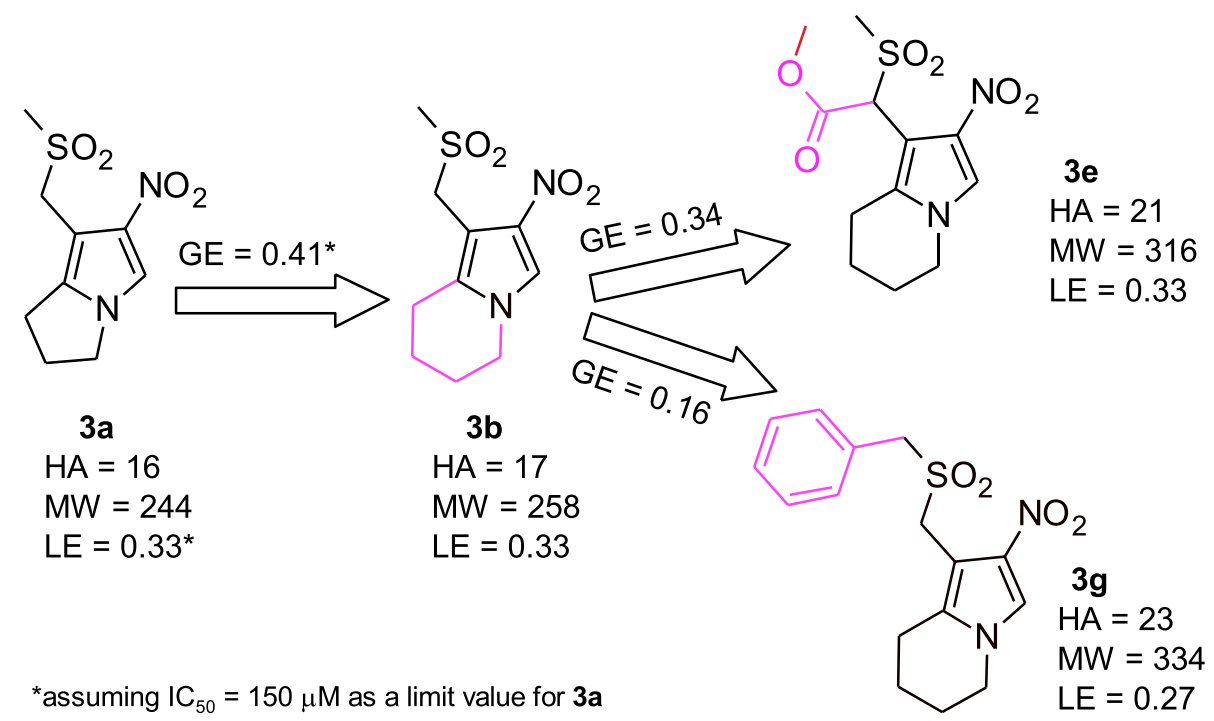

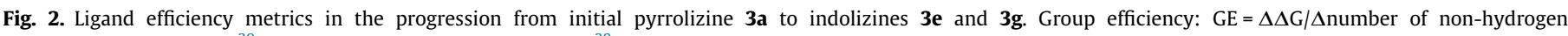
atoms $=\Delta 1.37 \mathrm{pIC}_{50} / \Delta \mathrm{HA} ;^{39}$ Ligand efficiency: $\mathrm{LE}=1.37 \mathrm{pIC}_{50} / \mathrm{HA}^{38}$ 


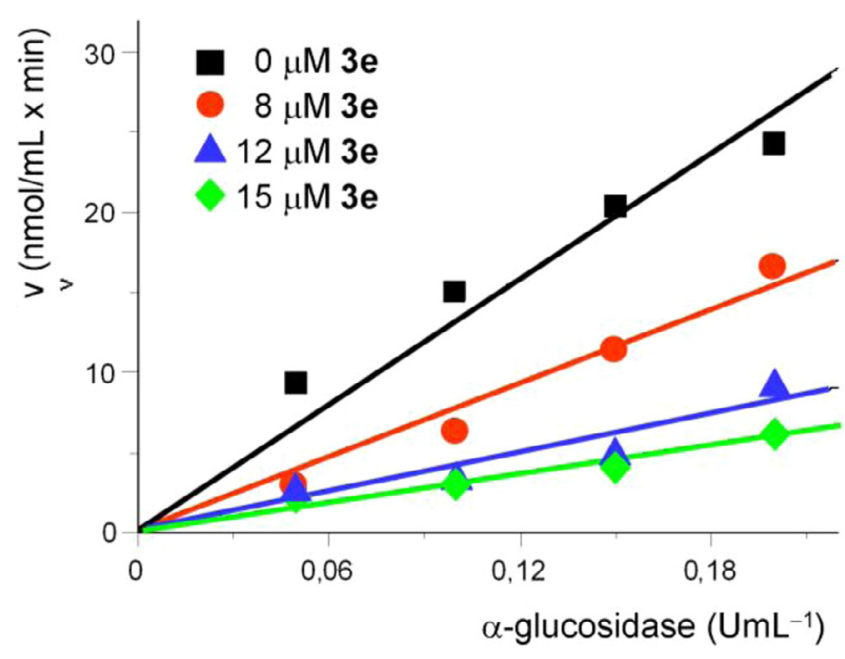

Fig. 3. Catalytic activity of $\alpha$-glucosidase as a function of enzyme concentration at different inhibitor (3e) concentrations.

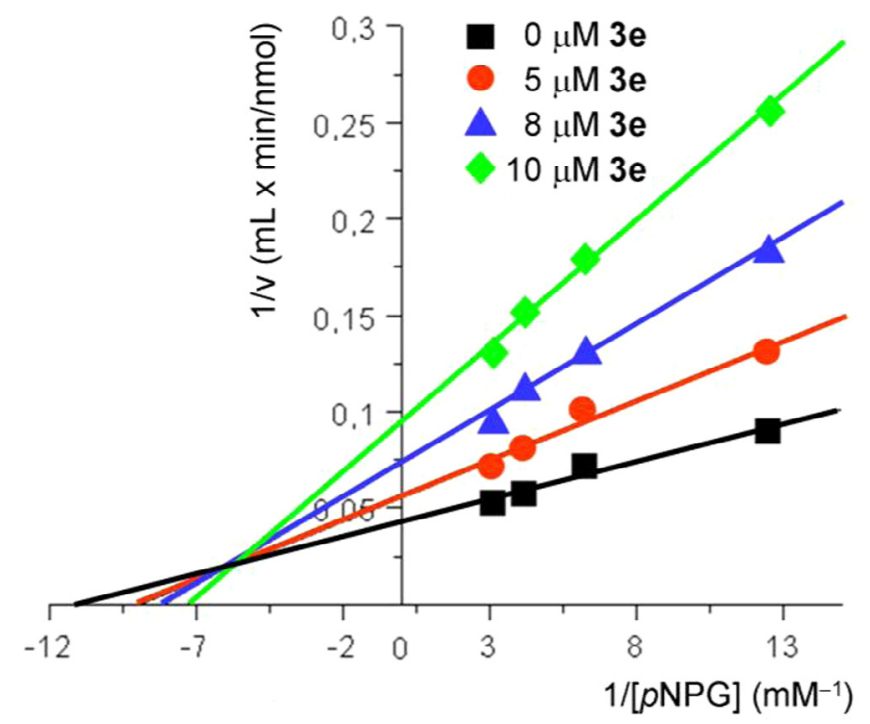

Fig. 4. Lineweaver-Burk plot analysis of the kinetics of $\alpha$-glucosidase inhibition exerted by compound $\mathbf{3 e}$. and phenyl substituents were not independent (i.e., they are not additive) since compound $\mathbf{3 h}$ was less active than $\mathbf{3 e}$ and was only poorly more active than $\mathbf{3 g}$. Thus, the two substituents probably share the same interaction site and/or mutually constrain their respective orientations in an unfavorable overall arrangement. On the other hand, the possibility of detrimental excessive lipophilicity should not be excluded with this hypothesis including also the detrimental effect of the $p$-methyl substituent in $\mathbf{3 i}$.

To investigate the mechanism of action of the title compounds on $\alpha$-glucosidase, a kinetic study was performed on the most active congener, the ester $\mathbf{3 e}$. The reversibility of $\mathbf{3 e}$ inhibition was first assessed by evaluating the initial rate of the $\alpha$-glucosidase promoted reaction versus enzyme concentration at various inhibitor concentrations (Fig. 3). A family of straight lines all passing through the origin was obtained. The line gradients decreased with increasing inhibitor concentration and this indicated that compound 3e was a reversible inhibitor.

Then, the initial rates at various concentrations of substrate ( $p$ NPG, $p$-nitrophenyl $\alpha$-D-glucopyranoside) in the absence and in the presence of different concentrations of compound $\mathbf{3 e}$ were studied. The data, analysed in double reciprocal (Lineweaver-Burk) plot (Fig. 4) were interpolated by four straight lines which showed a common intersection point in the second quadrant, typical of mixed inhibition. $K_{\mathrm{m}}$ value increases from 0.092 (control) to $0.14 \mathrm{mM}$ and $V_{\max }$ value decreases from 23.8 to $10.7 \mathrm{nmol} / \mathrm{min}$ $\mathrm{mL}$ with increasing concentration of $\mathbf{3 e}$.

A mixed-type inhibition can be described by the following double reciprocal equation: ${ }^{40}$

$\frac{1}{v}=\frac{K_{\mathrm{m}}}{V_{\max }}\left(1+\frac{[\mathrm{I}]}{K_{\mathrm{i}}}\right) \frac{1}{[\mathrm{~S}]}+\frac{1}{V_{\max }}\left(1+\frac{[\mathrm{I}]}{\alpha K_{\mathrm{i}}}\right)$

where $v$ is the enzyme reaction velocity; $K_{\mathrm{m}}$ and $K_{\mathrm{i}}$ are the Michaelis-Menten and the inhibition constants, respectively; [I] and [S] are the concentrations of $\mathbf{3 e}$ and substrate ( $p$-NPG), respectively. From this equation, secondary equations may be derived and these, in turn, correspond to secondary plots that allow extrapolation of the inhibition constants $K_{\text {i,free }}$ (i.e., a measure of the affinity of $\mathbf{3 e}$ for the free enzyme) and $K_{\text {i,bound }}$ (i.e., a measure of the affinity of 3e for the complex enzyme-substrate). In fact, the following two equations may be derived:

$$
\text { slope }=\frac{K_{\mathrm{m}}}{V_{\max }}\left(1+\frac{[\mathrm{I}]}{K_{\mathrm{i}}}\right) \quad \text { Y-intercept }=\frac{1}{V_{\max }}\left(1+\frac{[\mathrm{I}]}{\alpha K_{\mathrm{i}}}\right)
$$
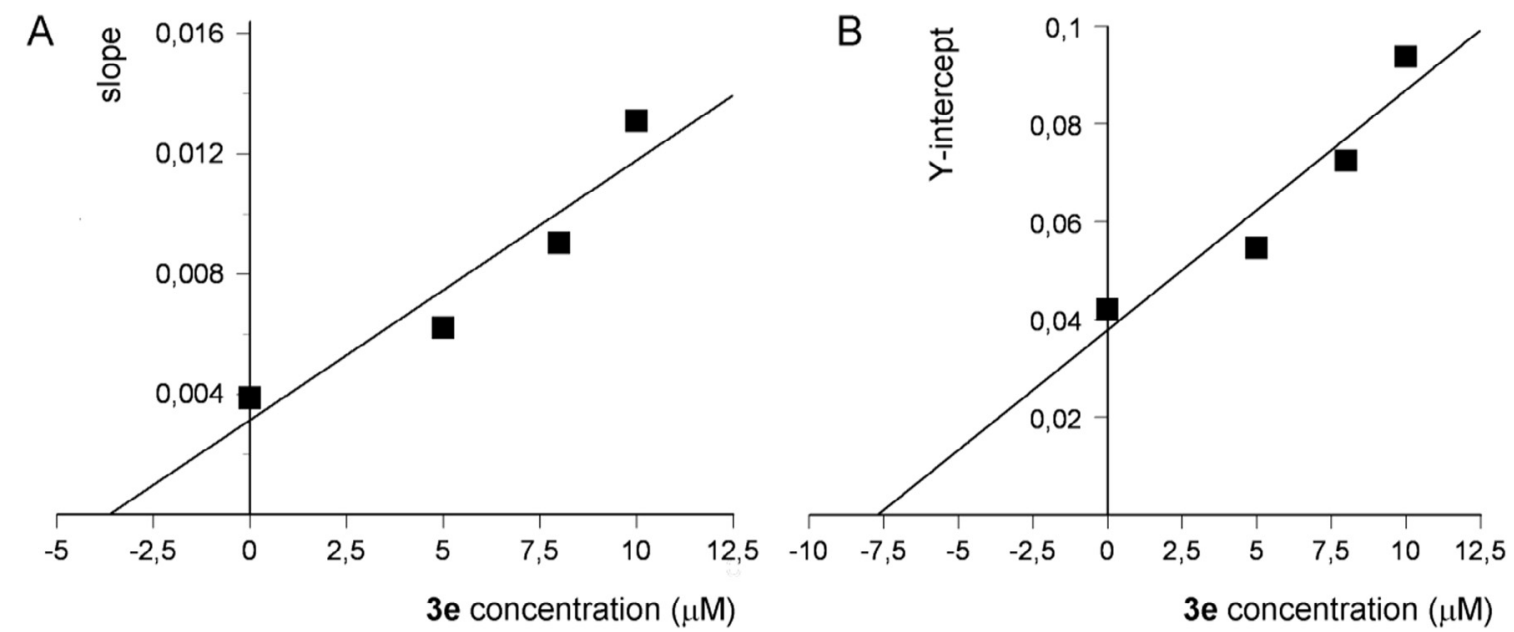

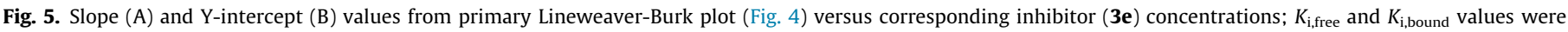
obtained as the absolute values of the concentration-axis intercepts of plots A and B, respectively. 
By re-plotting the slope and Y-intercept values taken from each line in the primary Lineweaver-Burk plot (Fig. 4) versus various corresponding concentrations of $\mathbf{3 e}$ two secondary plots were obtained (Fig. 5A and B, respectively). $K_{\mathrm{i}, \text { free }}$ and $K_{\mathrm{i}, \text { bound }}$ values were obtained as the absolute values of the concentration-axis intercepts of plots A and B, respectively. ${ }^{41}$ Since $K_{\mathrm{i}, \text { free }}$ value $(3.6 \mu \mathrm{M})$ was lower than $K_{\mathrm{i}, \text { bound }}$ value $(7.6 \mu \mathrm{M})$, the compound $3 \mathbf{e}$ binds preferentially the free $\alpha$-glucosidase form than the $\alpha$-glucosidase-substrate complex.

To investigate possible conformational changes determined by the interaction of $\mathbf{3 e}$ with its target enzyme, circular dichroism (CD) spectra of $\alpha$-glucosidase were recorded in the absence and in the presence of increasing concentrations of the inhibiting small-molecule (Fig. 6). The changes induced by increasing concentrations of $\mathbf{3 e}$ were similar to those displayed by a recently reported mixed-type $\alpha$-glucosidase inhibitor and denote reduction of the percentages of $\alpha$-helices and $\beta$-sheets in the overall secondary structure of the enzyme. ${ }^{40}$

The above findings were further supported by a molecular docking study. Since the crystallographic structure of Saccharomyces cerevisiae $\alpha$-glucosidase is not available, a comparative 3D structural model of the yeast $\alpha$-glucosidase (maltase) protein was prepared by using Modeller. ${ }^{42}$ The $3 \mathrm{D}$ modeling was performed according to our validated protocols. ${ }^{43}$ The 3D isomaltase crystallographic structure of Saccharomyces cerevisiae isomaltase (PDB_ID: 3axh.pdb) was used as a protein template for building the yeast $\alpha$-glucosidase 3D model, sharing more than $72 \%$ of identical residues with the former (Fig. 1 in the Supplementary data). We used the obtained 3D comparative model for performing docking analyses according to our protocols validated also by redocking. ${ }^{43,44}$

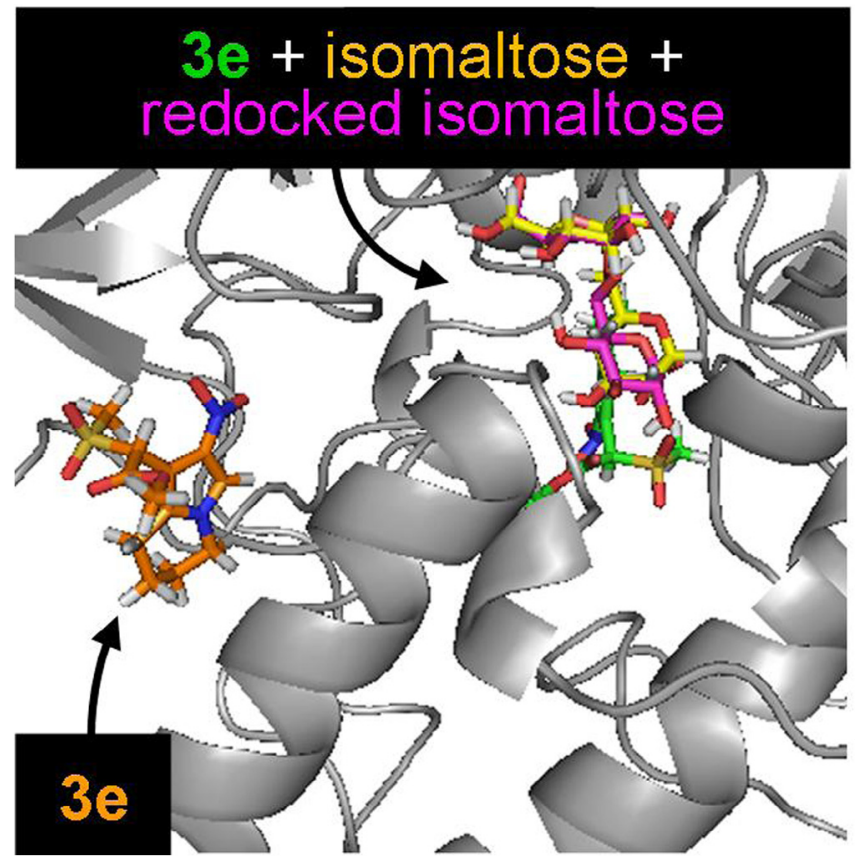

Fig. 7. Blind docking results. The 3D comparative model of $\alpha$-glucosidase is reported in cartoon representation. The best ligand (3e) pose obtained by docking the ligand within the substrate binding site (green sticks) and the best ligand pose within one out of three clusters (orange sticks) are reported. The crystallized isomaltose and the redocked isomaltose are also reported for comparative purposes (yellow and magenta sticks, respectively). For a list of interacting residues, see Table 2 and S2 (supplementary materials).

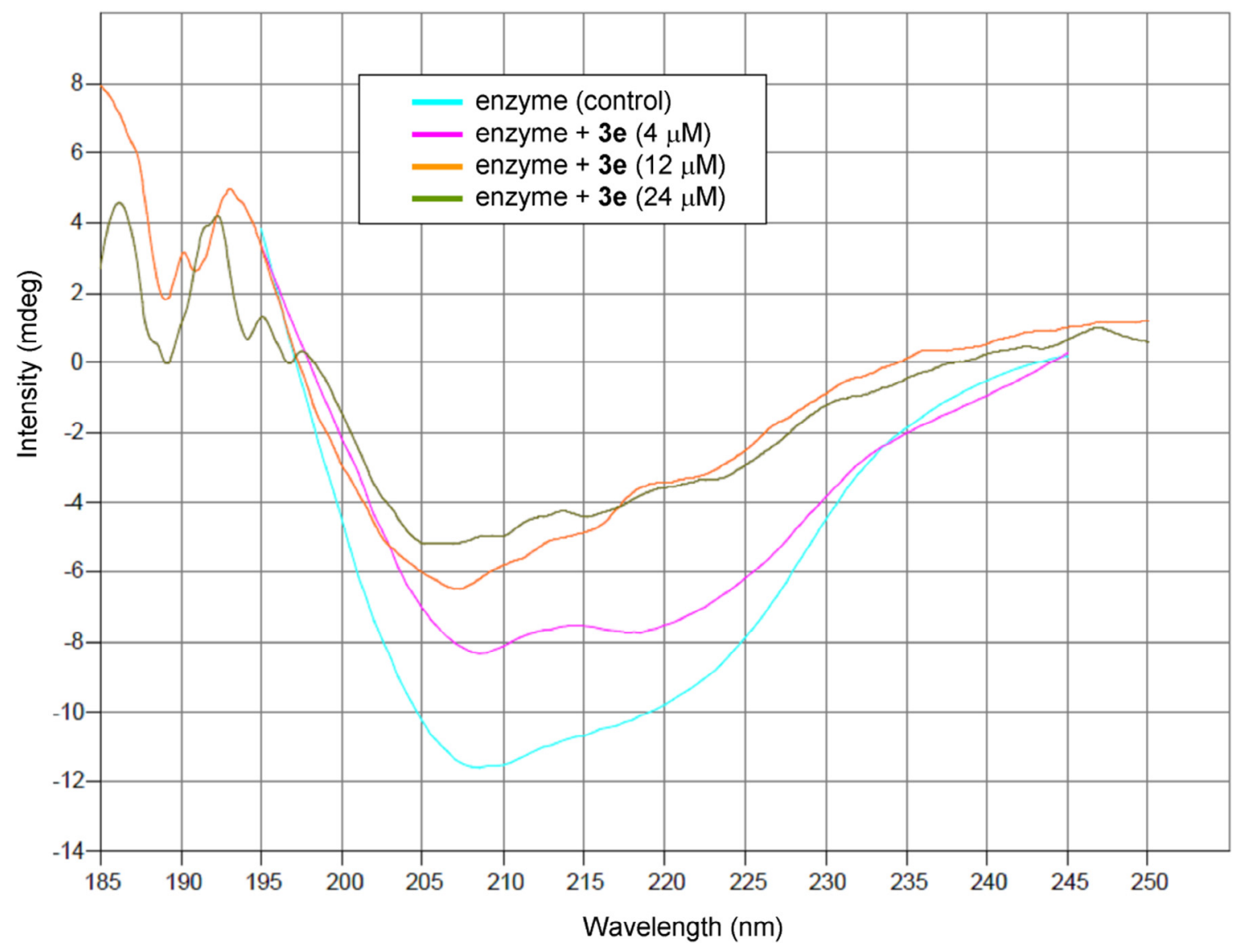

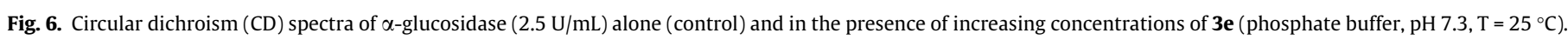


The re-docking simulation allowed us to define a specific gridbox for the isomaltase that reproduced the crystallized protein-ligand complex with high fidelity. The root mean square deviation (RMSD) between the coordinates of the ligand (isomaltose) in the crystallized complex (isomaltase-isomaltose) and the best "re-docked" pose coordinates, obtained by using Autodock, ${ }^{45}$ was equal to $0.6 \AA$. Given the high percentage of identical amino acids that isomaltase shares with the yeast $\alpha$ glucosidase, the same gridbox could be used for investigating the possible binding region of other substrates and competitive inhibitors to maltase.

By docking 3e within the substrate binding region we obtained a pose of the ligand interacting with only some of the residues of the substrate binding site (Fig. 7). In particular, Phe157 and Phe177 seem to be involved in hydrophobic interactions (Tables 2 and S2 in the supplementary data).

When performing a blind docking run involving the overall structure of our 3D comparative model, three other main putative binding regions where found (Fig. S1 and Table S2 in the supplementary data), with the closest to the catalytic site being reported in Fig. 7. These findings are in agreement with the results obtained from kinetic studies.

The phenyl-substituted analog $\mathbf{3 h}$ and DNJ were docked in the $\alpha$-glycosidase binding site for comparative purposes (Fig. 8). Residues within $4 \AA$ from the three docked molecules are reported in Table 2. It appears that the piperidine moiety
A

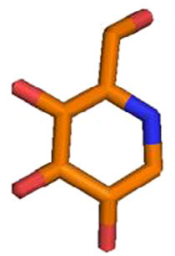

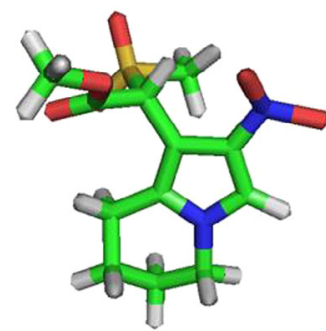
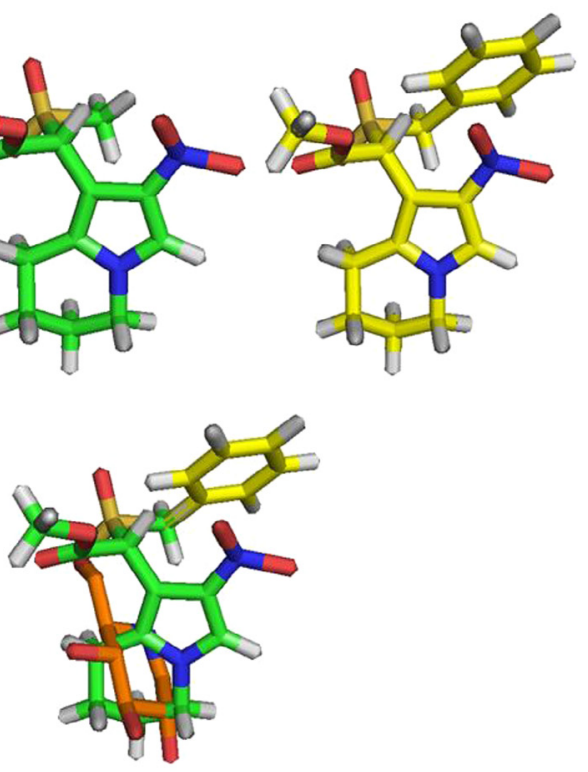

C

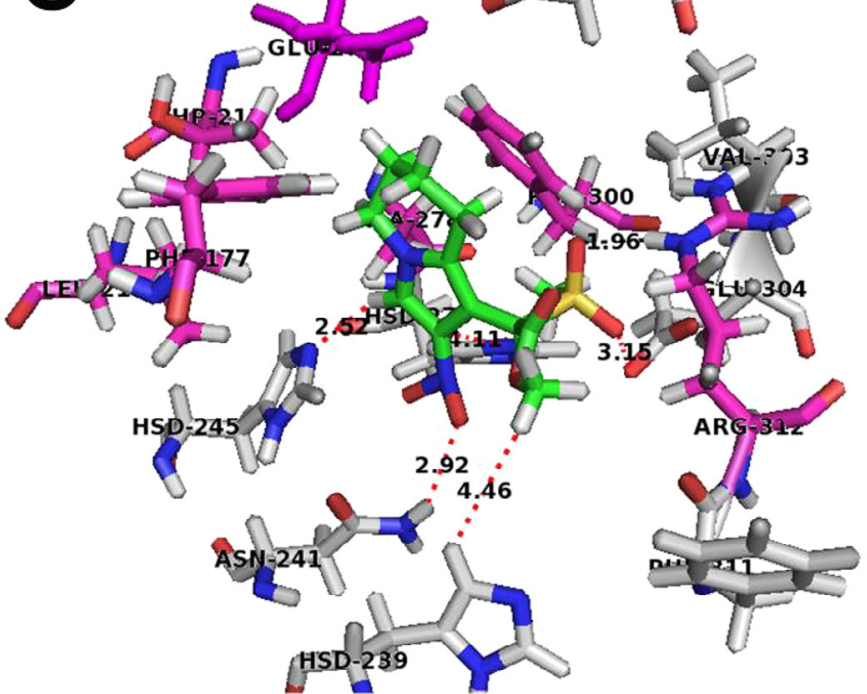

B
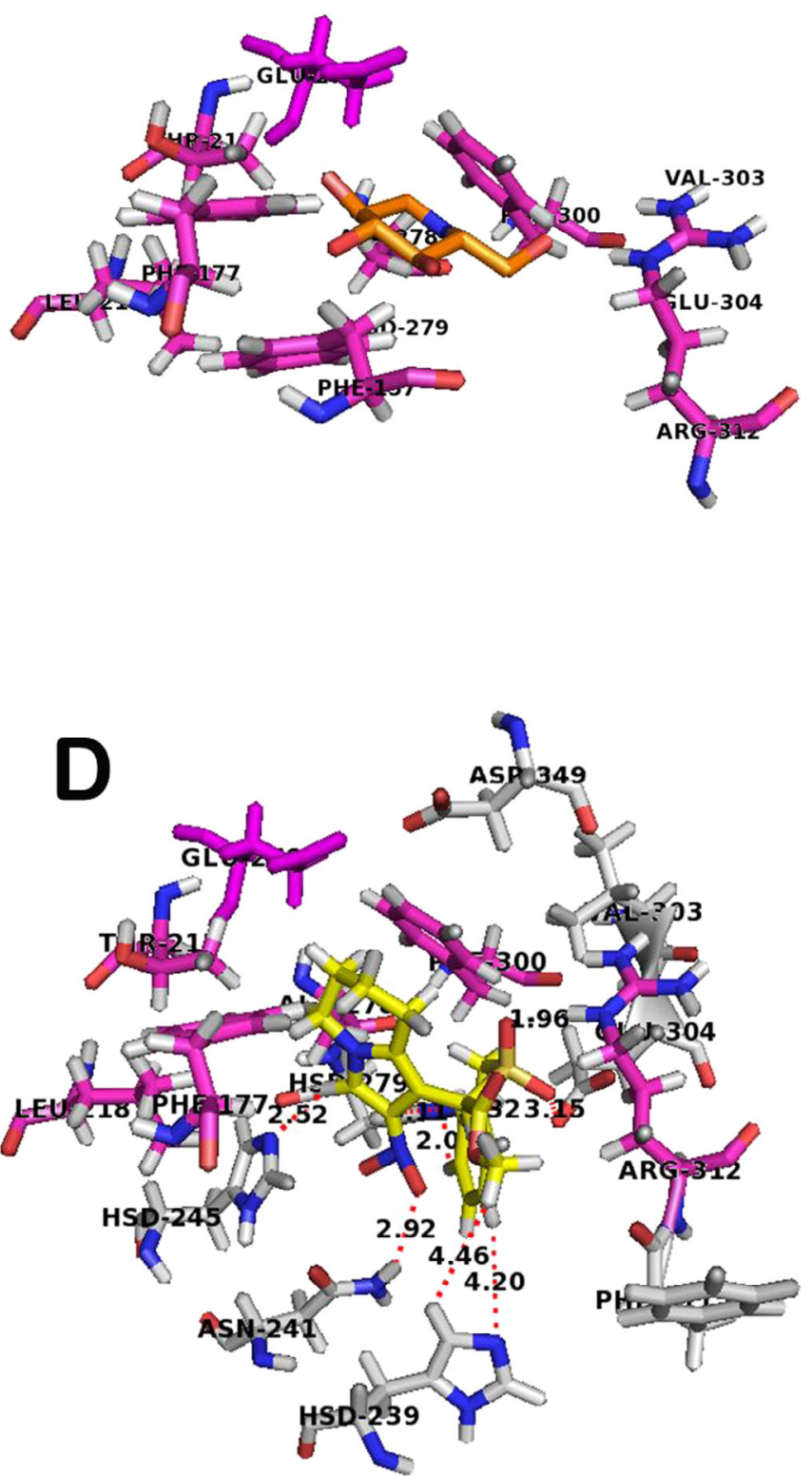

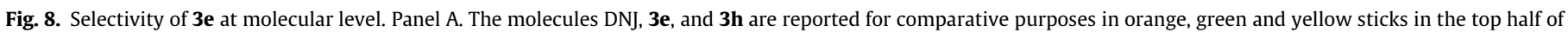

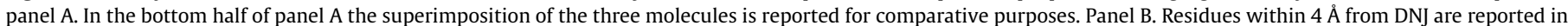

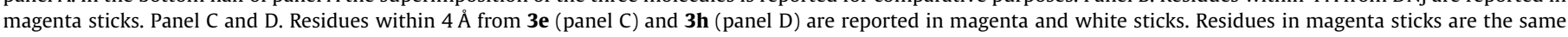

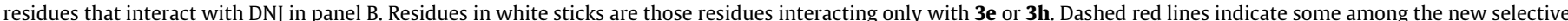

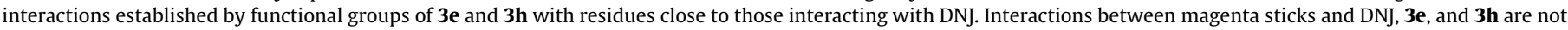
reported for the sake of clarity. 
Table 2

Docking study on $\mathbf{3 e}$, DNJ, and $\mathbf{3 h}$ : interacting residues.

\begin{tabular}{lll}
\hline $\begin{array}{l}\text { Residues within } 4 \AA \\
\text { from 3e }\end{array}$ & $\begin{array}{l}\text { Residues within 4 } \\
\text { from DNJ }\end{array}$ & $\begin{array}{l}\text { Residues within } 4 \AA \\
\text { from } \mathbf{3 h}\end{array}$ \\
\hline F157 & F157 & F157 \\
F177 & F177 & F177 \\
T215 & T215 & T215 \\
L218 & L218 & L218 \\
H239 & & H239 \\
N241 & & N241 \\
H245 & E276 & H245 \\
E276 & A278 & E276 \\
A278 & & A278 \\
H279 & F300 & H279 \\
F300 & & F300 \\
V303 & & V303 \\
E304 & & E304 \\
& & P309 \\
F311 & & F311 \\
R312 & R312 & R312 \\
D349 & & D349 \\
\hline
\end{tabular}

of $\mathbf{3 e}$ and $\mathbf{3 h}$ is able to establish the same interactions established by DNJ with the $\alpha$-glucosidase binding region. The higher affinity shown by $\mathbf{3 e}$ and $\mathbf{3 h}$ is due to new interactions established by the pyrrolidine ring and the nitro-group with $\mathrm{H} 245$, $\mathrm{H} 279$, and $\mathrm{N} 241$; by the $\mathrm{CO}_{2} \mathrm{Me}$ with $\mathrm{H} 239$; by the nitro-group and $\mathrm{H} 239$, and by the stronger interaction established between the $\mathrm{SO}_{2} \mathrm{CH}_{3}$ and $\mathrm{R} 312$. More in general, if the piperidine ring is replaced with a ring greater or smaller, the resulting molecules are less able to fit correctly the binding cavity of the investigated $\alpha$-glucosidase.

The presence of a phenyl or a tolyl result in a loss of efficiency of the corresponding inhibitors ( $\mathrm{cf}$. $\mathbf{3 i}, \mathbf{3 h}$, and $\mathbf{3 e}$ ). The presence of the phenyl moiety could be able to re-orient the ligand in the binding site worsening its fitting and displaying new interactions (i.e. with P309).

Similarly, the replacement of $\mathrm{CO}_{2} \mathrm{Me}$ at $\mathrm{R}^{1}$ with a $\mathrm{H}$-atom, also in presence of a phenyl group in place of $\mathrm{R}^{2}$, or the replacement of both $\mathrm{R}^{1}$ and $\mathrm{R}^{2}$ with two $\mathrm{H}$-atoms cause reduction of affinity (cf. 3b, 3g, 3e, and $\mathbf{3 h}$ ) most likely due to the loss of interactions with $\mathrm{H} 239$ and a greater rotation freedom of the nitro-group.

In conclusion, we have designed and prepared a series of 1[(methylsulfonyl)methyl]-2-nitro-5,6,7,8-tetrahydroindolizines and homologs as non-sugar-type $\alpha$-glucosidase inhibitors. The majority of the tested compounds were more potent than DNJ, a well-known $\alpha$-glucosidase inhibitor. The most potent compound, the tetrahydroindolizine $\mathbf{3 e}$, displayed a 25 -fold higher inhibitory activity than the reference compound and behaves as mixed inhibitor with preference for the free enzyme over the $\alpha$-glucosidasesubstrate complex. CD and docking studies supported kinetic results. Considering the relatively low molecular weight of $\mathbf{3 e}$ together with its good ligand metrics, this nitro-substituted tetrahydroindolizine may be considered as a good starting point towards new leads in the area of $\alpha$-glucosidase inhibitors.

\section{Acknowledgements}

The authors thank the Ministero dell'Istruzione, dell'Università e della Ricerca (MIUR - Italy) (Project PRIN 2010FPTBSH_005 "NANO Molecular tEchnologies for Drug delivery e NANOMED") for financial help.

\section{A. Supplementary data}

Supplementary data (synthetic procedures and characterization for all new compounds, general procedures for biological activity evaluation, and details about the docking study) associated with this article can be found, in the online version, at http://dx.doi. org/10.1016/j.bmcl.2017.07.068. These data include MOL files and InChiKeys of the most important compounds described in this article.

\section{References}

1. Okuyama M, Saburi W, Mori H, Kimura A. Cell Mol Life Sci. 2016;73:2727-2751.

2. Kalra S, Chadha M, Sharma SK, Unnikrishnan AG. Indian I Endocrinol Metab. 2014;18:138-141.

3. Raben N, Plotz P, Byrne BJ. Curr Mol Med. 2002;2:145-166.

4. Corfield AP, Myerscough N. Glycosidase Activity. In: Corfield AP, ed Glycoprotein Methods and Protocols: The Mucins. Totowa, NJ: Humana Press; 2000:403-416.

5. Qu X, Pan X, Weidner J, et al. Antimicrob Agents Chemother. 2011;55:1036-1044.

6. van de Laar FA, Lucassen PL, Akkermans RP, Van de Lisdonk EH, Rutten GE, van Weel C. Diabetes Care. 2005;28:166-175.

7. Nagai E, Katsuno T, Miyagawa J, et al. Endocr J. 2011;58:869-877.

8. Dash S, Crisp S, Hartnell S, et al. Diabetes Res Clin Pract. 2012;95:e49-e51.

9. Buschur E, Brown F, Wyckoff J. Curr Diabetes Rep. 2015;15:4.

10. Ghody P, Shikha D, Karam J, Bahtiyar G. Maturitas. 2015;81:282-286.

11. Hermansen K, Mortensen LS. Drug Saf. 2007;30:1127-1142.

12. Hanefeld M, Cagatay M, Petrowitsch T, Neuser D, Petzinna D, Rupp M. Eur Heart J. 2004;25:10-16.

13. Gerber-Lemaire S, Juillerat-Jeanneret L. Mini-Rev Med Chem. 2006:6:1043-1052.

14. Norez C, Noel S, Wilke M, et al. FEBS Lett. 2006;580:2081-2086.

15. Bin B-H, Seo J, Yang SH, et al. Exp Dermatol. 2013;22:541-546.

16. Zhu J-H, Zhang D, Chen W. Afr I Tradit Complement Altern Med. 2013;10:356-359.

17. Platt FM, Butters TD. Expert Rev Mol Med. 2004;2:1-17.

18. Sechi A, Dardis A, Zampieri S, et al. Orphanet J Rare Disease. 2014;9:143.

19. Chang J, Block TM, Guo J-T. Antiviral Res. 2013;99:251-260.

20. Ghani U. Eur J Med Chem. 2015;103:133-162.

21. Hopkins AL, Keserü GM, Leeson PD, Rees DC, Reynolds CH. Nat Rev Drug Discov 2014:13:105-121.

22. Taylor DL, Nash R, Fellows LE, Kang MS, Tyms AS. Antiviral Chem Chemother. 1992;3:273-277.

23. Lahiri R, Ansari AA, Vankar YD. Chem Soc Rev. 2013;42:5102-5118.

24. Pascale R, Carocci A, Catalano A, et al. Bioorg Med Chem. 2010;18:5903-5914.

25. Dale MP, Ensley HE, Kern K, Sastry KAR, Byers LD. Biochemistry. 1985;24:3530-3539.

26. Heightman TD, Vasella AT. Angew Chem Int Ed. 1999;38:750-770.

27. Gao K, Zheng C, Wang T, et al. Molecules. 2016;21:11. http://dx.doi.org 10.3390/molecules21111600.

28. Leeson PD, Springthorpe B. Nat Rev Drug Discov. 2007;6:881-890.

29. Ritchie TJ, MacDonald SJF, Young RJ, Pickett SD. Drug Discovery Today. 2011;16:164-171.

30. Bianchi L, Maccagno M, Petrillo G, Scapolla C, Tavani C, Tirocco A. Eur J Org Chem. 2014;39-43.

31. Gualdani R, Cavalluzzi MM, Lentini G, Habtemariam S. Molecules. 2016;21:11 http://dx.doi.org/10.3390/molecules21111530.

32. Lovering F, Bikker J, Humblet C. J Med Chem. 2009;52:6752-6756.

33. Gualdani R, Cavalluzzi MM, Lentini G. Curr Med Chem. 2016;23:2289-2332.

34. Novi M, Guanti G, Dell'Erba C, Spinelli D. J Chem Soc, Perkin Trans 1 1976;2264-2266.

35. Spinelli D, Guanti G, Dell'Erba C. J Chem Soc, Perkin Trans 2. 1972;441-445.

36. De Melo EB, da Silveira Gomes A, Carvalho I. Tetrahedron. 2006;62:10277-10302.

37. Leeson PD, Springthorpe B. Nat Rev Drug Discov. 2007;2007:881-890.

38. Hopkins AL, Groom CR, Alex A. Drug Discovery Today. 2004;9:430-431.

39. Verdonk ML, Rees DC. ChemMedChem. 2008;3:1179-1180.

40. Fang Y, Wang S, Wu J, Zhang L, Wang Z. Food Funct. 2017;8:323-332.

41. He Y, Wang XB, Fan BY, Kong LY. Bioorg Med Chem. 2014;22:762-771.

42. Sánchez R, Sali A. Methods Mol Biol. 2000:143:97-129.

43. Pierri CL, Parisi G, Porcelli V. Biochim Biophys Acta. 2010;1804:1695-1712.

44. Todisco S, Di Noia MA, Onofrio A, et al. Biochem Pharmacol. 2016;100:112-132.

45. Goodsell DS, Morris GM, Olson AJ. J Mol Recognit. 1996;9:1-5. 